\title{
Is double-approach surgery and tenodesis without a gastrocnemius flap better for dealing with proximal fibular osteosarcoma?
}

\author{
Jun Wan, Can Zhang and Hong-bo He
}

\begin{abstract}
Background: Resection of proximal fibular osteosarcoma involving the posteromedial aspect of the fibula is challenging. Reconstruction using a gastrocnemius flap may result in significant lateral instability and abnormal knee movement. Furthermore, postoperative gait may be disturbed by foot drop resulting from scarification of the common peroneal nerve.

Methods: Between January 2011 and December 2013, five patients with proximal fibular osteosarcoma were treated via the double-approach procedure using en bloc resection without a gastrocnemius flap. Simultaneously, all patients received one-stage tenodesis of the anterior tibial and toe extensor tendons. Clinical outcomes, including local tumor recurrence, complications, and functional outcomes, were evaluated.

Results: The mean follow-up duration was 47.2 months (range 42-52 months). No patients experienced local recurrence. The patients' Enneking functional scores were excellent (80\%) or good (20\%) at the final follow-up.

Conclusions: In patients with proximal fibular osteosarcoma, the double-approach procedure allows easier and safer en bloc tumor resection with vessel and nerve protection. One-stage tenodesis without a gastrocnemius flap is associated with good functional outcomes.
\end{abstract}

Keywords: Double approach, Proximal fibular, Osteosarcoma, Gastrocnemius flap, Tenodesis

\section{Background}

As the most common primary malignant bone tumor, osteosarcoma usually involves the metaphyses of the distal femur, proximal tibia, or proximal humerus. In contrast, the proximal fibula is an uncommon site for osteosarcoma. Treatment typically includes preoperative neoadjuvant chemotherapy, surgical resection, and postoperative adjuvant chemotherapy. Joint-sparing procedures with wide surgical margins are the standard surgical intervention.

Described by Malawer, type-II resection is most appropriate for dealing with proximal fibular osteosarcoma. However, if there is marked tumor involvement in the posteromedial region, which is near to the posterior

* Correspondence: 1147820020@qq.com

Department of Orthopaedics, Xiangya Hospital, Central South University,

Xiangya Road 87\#, Changsha 410008, Hunan, People's Republic of China tibial vessels and nerves, amputation is generally selected because of the difficulty of achieving a wide surgical margin [1]. Also, reconstruction using a gastrocnemius flap may result in significant lateral instability and abnormal knee movement [2]. Furthermore, postoperative gait may be disrupted by foot drop resulting from scarification of the common peroneal nerve, which is unacceptable even with ankle-foot orthosis (AFO) [3].

Therefore, we asked the following questions: (1) Is double-approach surgery more appropriate for dealing with proximal fibular osteosarcoma, especially when there is tumor involvement in the posteromedial region? (2) Is one-stage tenodesis an alternative to AFO for dealing with foot drop caused by scarification of the common peroneal nerve? (3) Can better gait be obtained using one-stage tenodesis without a gastrocnemius flap? 


\section{Methods}

We performed a retrospective analysis of the clinical medical records, radiography findings, and histologic results of patients treated in our department between January 2011 and December 2013. Patients were eligible for inclusion if they had proximal fibular osteosarcoma histologically proven by core needle biopsy and underwent one-stage en bloc tumor resection via the doubleapproach procedure and tenodesis of the anterior tibial and toe extensor tendons without a gastrocnemius flap. Patients with multiple lesions of osteosarcoma or metastasis were excluded from the study. The study was conducted in accordance with the Declaration of Helsinki and with approval from the Ethics Committee of our hospital. Written informed consent was provided by all patients for the use of their medical information.

All patients had stage-IIB tumors according to the Enneking staging system [4]. A neoadjuvant chemotherapy protocol was administered to all patients (cisplatin $120 \mathrm{mg} / \mathrm{m}^{2}$, ifosfamide $3 \mathrm{~g} / \mathrm{m}^{2} /$ day, and doxorubicin $30 \mathrm{mg} / \mathrm{m}^{2} /$ day). After a two-cycle chemotherapy, the response was evaluated at a multidisciplinary oncologic meeting. All patients exhibited a good response to neoadjuvant chemotherapy before surgery (Fig. 1a, b). Meanwhile, an evaluation of the tibial and fibular arteries was performed using contrast-enhanced computed tomography to eliminate anatomic variations or vascular damage during chemotherapy. Then, modified Malawer type-II resection was conducted to achieve a negative surgical margin (Fig. $2 \mathrm{a}-\mathrm{c}$ ).

First, in contrast to the standard procedure of Malawer type-II resection, a posteromedial approach was used to expose the posteromedial portion of the tumor, vessels, and nerves in the posterior deep compartment of the leg. Using this approach, ligation of the anterior tibial and peroneal arteries was performed to secure a safer margin and improve tumor mobilization. Then, the posterior tibial artery and tibial nerve were preserved and moderately distracted under direct vision (Fig. 3a, b). Second, a longitudinal incision was made over the proximal fibula to allow excision of the biopsy site. Care was taken to leave a sleeve of normal soft tissue around the tumor in the proximal fibula. Osteotomy of the fibula was performed $2 \mathrm{~cm}$ distal to the tumor as indicated by contrast-enhanced magnetic resonance imaging. The common peroneal nerve was sacrificed for achieving sufficient surgical margin (Fig. 3c, d). The cut ends of the biceps femoris tendon and lateral collateral ligament (LCL) were re-anchored to the proximal tibial metaphysis and surrounding capsule for knee stability. A limited compression plate was used to avoid potential facture of the proximal tibia. The wound was closed in lane without a gastrocnemius flap. The anterior tibial and toe extensor tendons were stabilized using anchored screws with the ankle joint in a neutral position (Fig. 4a, b). Finally, histologic examination of the excised specimens was conducted to confirm the diagnosis of osteosarcoma and that the margins were tumor-free.

Two weeks after surgery, adjuvant chemotherapy was initiated and continued for six cycles. Early non-weightbearing mobilization was allowed by using a hinged knee brace 2 weeks after surgery. Then, full weight-bearing with the brace was permitted 6 weeks after surgery and continued without the brace after 12 weeks. All patients were assessed at 3-month intervals during the follow-up period. At each follow-up visit, routine examinations were performed to test for local recurrence and metastasis. Based on the Enneking functional evaluation scale, the results of functional assessments were recorded as excellent, good, fair, or poor [5].

\section{Results}

Five patients were enrolled in our study (three men and two women) with a mean age of 19.4 years (range

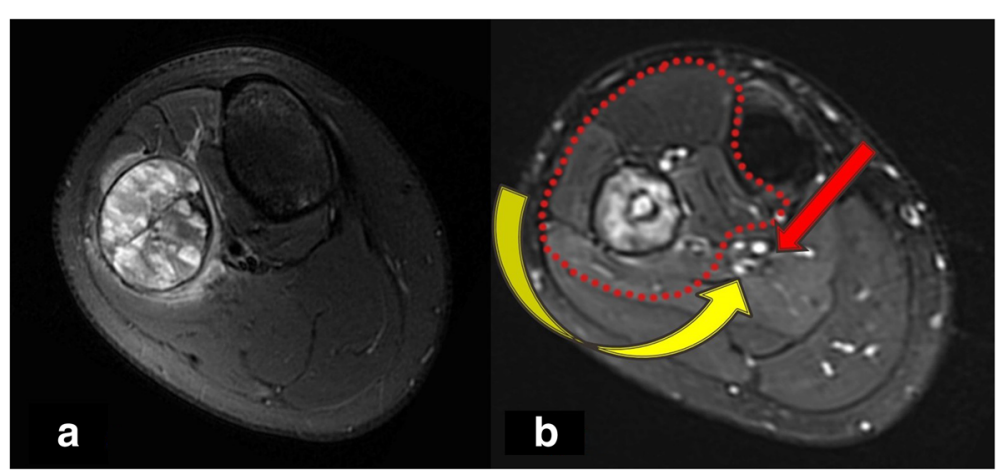

Fig. 1 a MRI (T2 weight imaging) revealed that the medial-posterior aspect of the proximal fibula was involved by tumor combined with the tibial vessels and nerve. $\mathbf{b}$ After adjuvant chemotherapy, good result was observed with obvious ossified shell formation and tumor shrink. However, in terms of handling the vessel and nerve, it is difficult to deal from one lateral approach (yellow arrow); we recommended the double approach (adding medial approach, red arrow) 


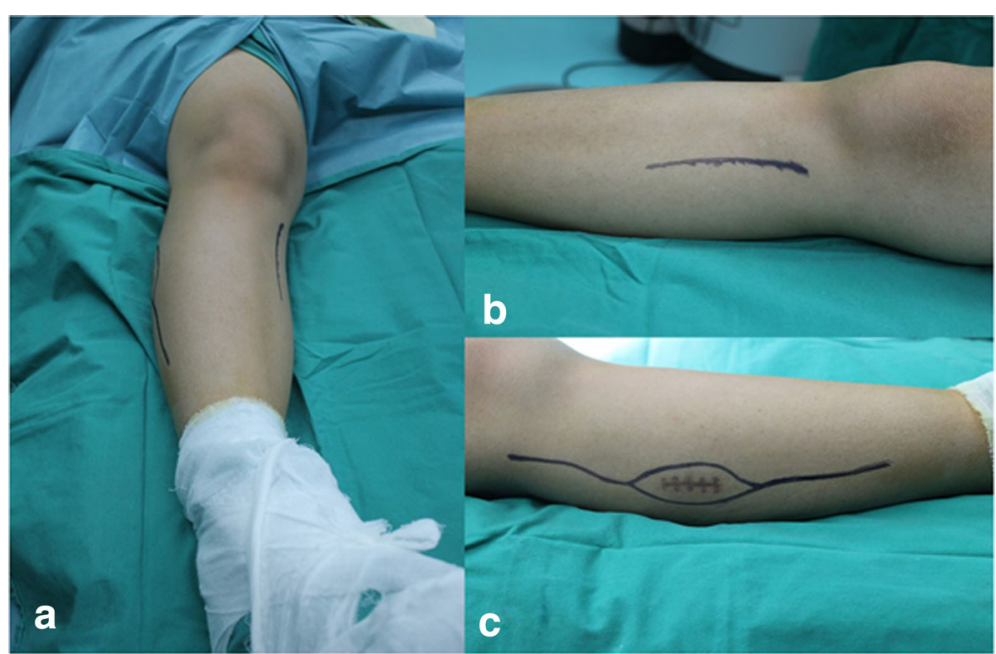

Fig. 2 a Gross view of the double approach in a patient's leg. b Gross view of the medial approach. c Gross view of the lateral approach

13-37 years). The mean follow-up duration was 47.2 months (range 42-52 months). At the last follow-up, no local recurrence was observed. A suspected lung nodule was found in the left lung of one patient (patient 5) at a follow-up examination at 48 months. One patient (patient 4) required wound debridement for superficial necrosis of the skin. All patients were able to walk without support at the final follow-up. The mean active range of motion of the knee was $143^{\circ}$ (range $120-150^{\circ}$ ) (e.g., patient 1; Fig. 5a-d). The functional results were excellent $(80 \%)$ or good $(20 \%)$ at the final follow-up, and no patients were classified as fair or poor (Table 1).

\section{Discussion}

As a result of advances in neoadjuvant chemotherapy, the long-term overall survival of osteosarcoma improved

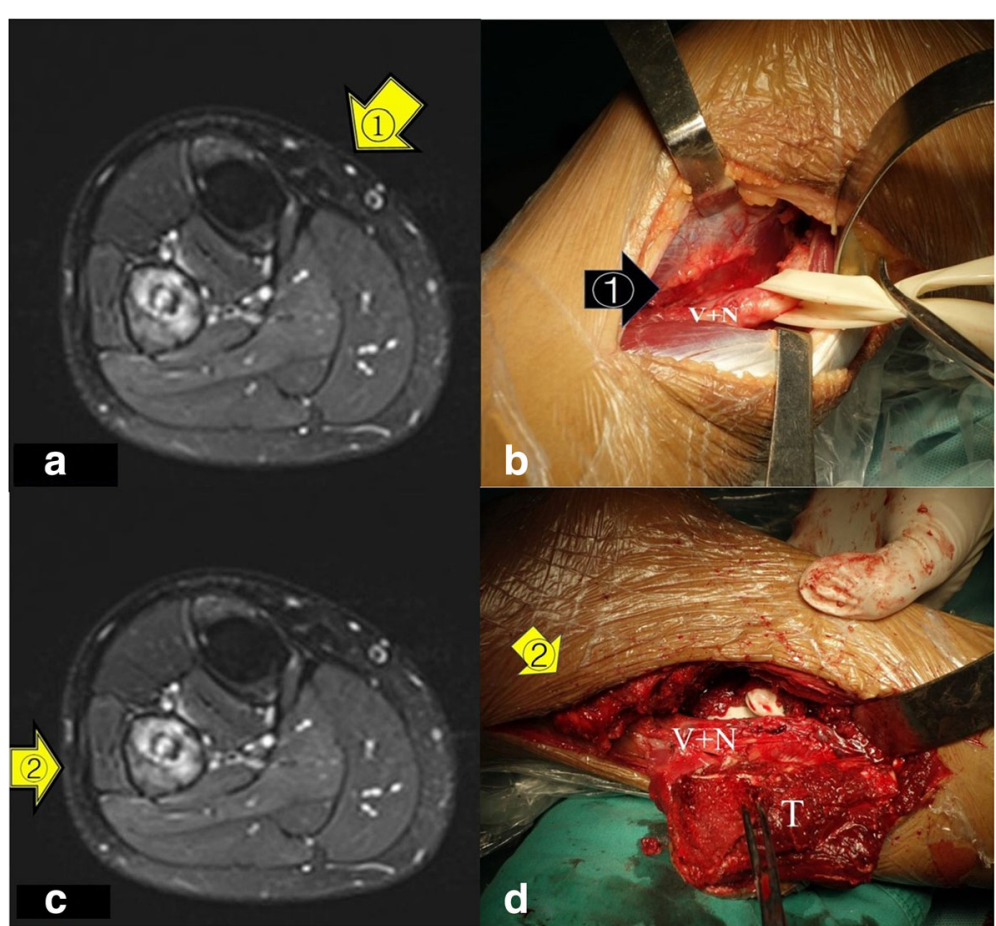

Fig. 3 a, b The first lateral approach (yellow arrow). Through this approach, the anterior tibial artery and the peroneal artery can be ligated easily to secure a safe margin and tumor mobilization; the posterior tibial artery and nerve could be preserved and moderately distracted under direct view (nerve and vessel $(\mathrm{N}+\mathrm{V})$ ). c c $\mathbf{d}$ The second lateral approach tumor en bloc resection (tumor $(\mathrm{T})$, nerve and vessel $(\mathrm{N}+\mathrm{V})$ ) 


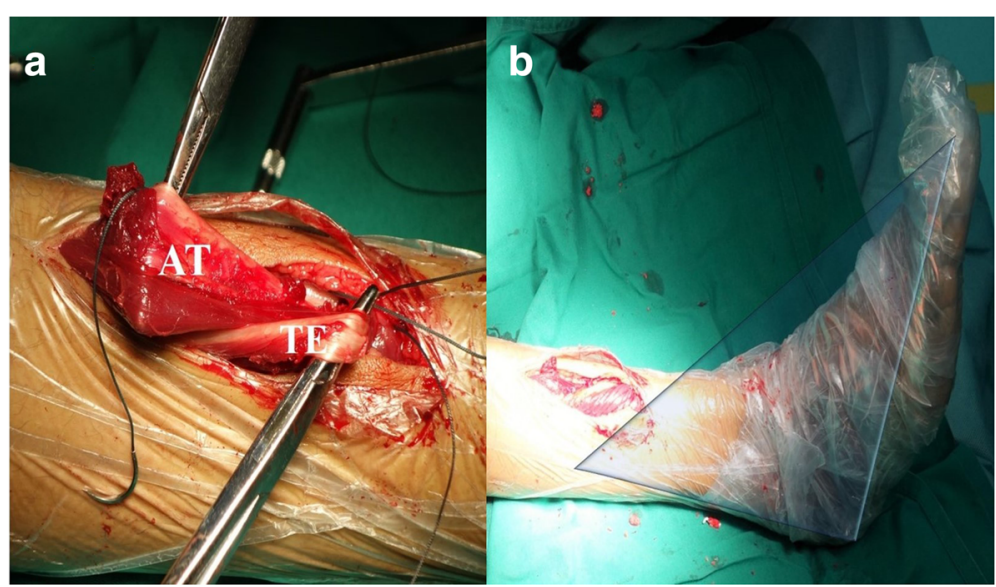

Fig. 4 The anterior tibial tendon and toe extensor were stabilized by using anchored screws (a) with neutral position of the ankle joint (b)

tremendously during the late twentieth century [6]. Limb-sparing surgery has attracted attention because of its enhanced social acceptance and limb function compared with amputation. In proximal fibular osteosarcoma, however, tumor involvement is likely in the posteromedial region, which is near the posterior tibial vessels and nerves; thus, amputation is chosen because of the difficulty of achieving a wide surgical margin.

Recently, several studies have shown that limbsparing surgery can be applied in patients who exhibit a good response to adjuvant chemotherapy [7]. A study by $\mathrm{Xu}$ et al. [8] showed that marginal resection had no negative impact on overall survival or local recurrence in patients who demonstrated a favorable response to chemotherapy. In another study by Kanazawa et al. [9], three patients were treated with intentional marginal resection of proximal fibular osteosarcoma. No local recurrence was observed and good functional results were achieved through preservation of the common peroneal nerve. Reddy et al. [10] analyzed 360 patients with osteosarcoma of the limb treated by two means: resection with close surgical margins or primary amputation. They concluded that amputation offered better local control, but had no clear survival benefit over resection with close margins.

In our case series, no patients experienced local tumor recurrence. This suggests that, even when proximal fibular osteosarcoma occupies a posteromedial position, joint-preserving surgery may be a viable and safe option in patients who exhibit good responses to neoadjuvant chemotherapy.

Malawer et al. [1] described two resection types, the indications of which depend on tumor differentiation: Malawer type-I resection, consisting of marginal resection of the proximal fibula with a small muscle layer, preserving the peroneal nerve and Malawer type-II resection, consisting of wide, extra-articular en bloc resection of the proximal fibula, anterior and lateral muscle groups, and common peroneal nerve. In patients with osteosarcoma, Malawer type-II resection is recommended for a safer surgical margin. However, it is hard to perform this technique through one longitudinal lateral approach if there is tumor involvement in the posteromedial region.

In this study, a modified Malawer type-II resection was used for tumor resection. Our procedure differed in
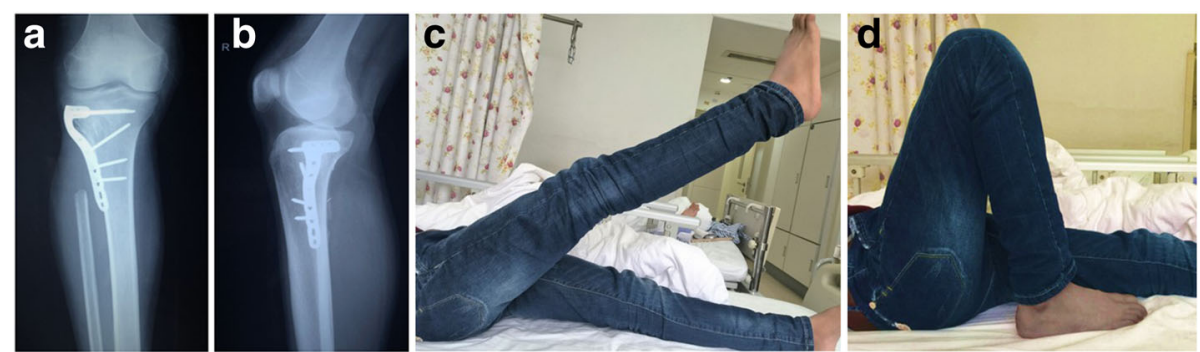

Fig. 5 Patient 1, a 16-year-old male, complained pain and limp in his right knee. Radiological reveal suspected proximal fibular osteosarcoma. A double-approach surgery with tenodesis was performed without gastrocnemius flap. At the final follow-up, no local recurrence was presented $(\mathbf{a}, \mathbf{b})$ and the patient was satisfactory with his excellent knee function and gait $(\mathbf{c}, \mathbf{d})$ 
Table 1 Patients' data

\begin{tabular}{|c|c|c|c|c|c|c|c|c|c|}
\hline $\begin{array}{l}\text { Case } \\
\text { no. }\end{array}$ & $\begin{array}{l}\text { Age } \\
\text { (years)/gender }\end{array}$ & $\begin{array}{l}\text { Length of the } \\
\text { tumor }(\mathrm{cm})\end{array}$ & $\begin{array}{l}\text { Longest diameter } \\
\text { of the tumor }(\mathrm{cm})\end{array}$ & $\begin{array}{l}\text { Complications+additional } \\
\text { procedure }\end{array}$ & $\begin{array}{l}\text { Follow-up } \\
\text { (months) }\end{array}$ & $\begin{array}{l}\text { Local } \\
\text { recurrence }\end{array}$ & Metastasis & $\begin{array}{l}\text { Enneking } \\
\text { score }\end{array}$ & $\begin{array}{l}\text { ROM of } \\
\text { knee joint }\end{array}$ \\
\hline 1 & $16 / M$ & 13.1 & 6.3 & None & 44 & None & None & Excellent & $150^{\circ}$ \\
\hline 2 & $15 / M$ & 13.6 & 5.2 & None & 52 & None & None & Excellent & $145^{\circ}$ \\
\hline 3 & $13 / F$ & 11.2 & 3.4 & None & 42 & None & None & Excellent & $150^{\circ}$ \\
\hline 4 & $37 / F$ & 10.2 & 3.7 & None & 48 & None & $\begin{array}{l}\text { Suspected lung } \\
\text { nodule }\end{array}$ & Good & $125^{\circ}$ \\
\hline 5 & $16 / M$ & 9.4 & 4.9 & $\begin{array}{l}\text { Skin necrosis }+ \\
\text { debridement }\end{array}$ & 50 & None & None & Excellent & $145^{\circ}$ \\
\hline
\end{tabular}

ROM range of motion

that a posteromedial approach was usually used to expose the vessels and nerves in the posterior deep compartment first. Through this approach, care should be taken to find these structures behind the tumor, which would usually be encountered through the lateral approach in standard Malawer type-II resection. The anterior tibial and peroneal arteries were ligated to secure a safe margin and improve tumor mobilization. Also, the posterior tibial artery and tibial nerve were preserved and distracted under direct vision through this approach, which provided more space for tumor resection.

Surgical treatment of proximal fibular osteosarcoma is challenging because the common peroneal nerve must be sacrificed in order to achieve negative surgical margins, resulting in iatrogenic foot drop. Permanent use of AFO causes muscle atrophy and paresthesia, both of which decrease functional outcomes. Reports in the literature show some loss of function even with use of a functional AFO. Patients also complain about the discomfort of using AFO use.

Tenodesis or tendon transfer is an appropriate alternative to the compensation for peroneal loss and eliminates the need for AFO use [11]. However, compared with simple tenodesis, the procedure of tendon transfer is time-consuming and requires some microsurgical techniques. In our patients, we performed one-stage tenodesis including stabilization of the anterior tibial muscles and toe extensor tendons. The purpose of this was to achieve early foot function without orthosis. All our patients have a satisfactory gait and are not willing to perform two-stage tendon-transfer surgery further (Additional file 1).

En bloc resection of the proximal fibula removes the attachments of the biceps femoris tendon and LCL. The biceps femoris tendon imparts a posteriorly directed dynamic restraint to anterior displacement of the proximal tibia and iliotibial band, providing anterior stability and reducing strain on the anterior cruciate ligament. The LCL provides the predominant resistance to varus rotation loading in the knee $[12,13]$. Thus, these lateral supporting structures must be meticulously repaired to prevent postoperative knee instability. Although good function has been reported without ligament reconstruction [14], fixation of the biceps femoris tendon and LCL to the tibial metaphysis is simple. Abdel et al. $[15,16]$ achieved longterm stability with ligament reconstruction in 112 patients with aggressive benign tumors and 53 patients with malignant fibular tumors. They asserted that, if possible, ligament reconstruction should be regarded as the standard procedure after fibular head resection, especially in young patients.

In Malawer type-II resection, a gastrocnemius flap is usually used for good cover of soft tissue. However, this procedure may cause additional mechanical problems. Kramers et al. [2] noted that abnormal gait could be observed in patients who accepted a gastrocnemius flap procedure. They think the possible reason could be that the knee develops a compensatory mechanism in the swing phase of the gait by increasing peak knee flexion. In our patients, we did not perform this reconstruction, but instead sutured the wound in lane. Only one patient experienced delayed wound healing requiring secondary wound debridement and suturing. We believe that the posteromedial incision made during the double approach reduced some of the tension when suturing the lateral incision, which contributed to wound healing. In selected patients, with precise ligament and soft-tissue suturing, the gastrocnemius flap procedure is not mandatory for soft-tissue reconstruction. In our case series, good functional outcomes of the knee joint were achieved with reattachment of the biceps femoris tendon and LCL and an intact gastrocnemius muscle (Fig. 5c, d).

In consideration of the possibility of bone weakness due to a shortage of soft-tissue coverage, local radiation for potential osteopenia, and pathologic fractures of the lateral tibia [17], a locking compression plate was used to support the lateral wall (Fig. 5a, b).

This study has several limitations. First, it involved a small number of patients with no control group. It was not possible to perform a comparative assessment of safety between the double and single approaches using our patients. Second, there is no consensus regarding the effects on gait of AFO and tenodesis. Third, 
although the risk of local recurrence was low at the end of the follow-up in our case series, it remains; recurrence may be evident in a longer follow-up period. A minimum follow-up duration of 5 years is necessary to confirm the safety of the procedure.

\section{Conclusions}

In selected patients with proximal fibular osteosarcoma, the double-approach procedure provides more space for local tumor resection and protection of the posterior vessels and nerves. One-stage tenodesis without a gastrocnemius flap achieves good functional results and a satisfactory gait. Although more experience and a longer follow-up are needed, this method may obtain better outcomes and limb function when performing Malawer type-II resection for proximal fibular osteosarcoma.

\section{Additional file}

Additional file 1: As presented in this video, patient 2 is satisfied with his gait in his daily life. He is not willing to perform two-stage tendontransfer surgery once more. (MOV $52410 \mathrm{~kb}$ )

\section{Acknowledgements}

We would like to thank Dr. Yu-peng Liu and Dr. Qing Liu for their hard work in language editing. We would like to thank Ms. Jing Wan (the wife of Dr. Jun Wan) for her selfless support during the period of this study.

\section{Funding}

This study was supported by the National Natural Science Foundation of China (NOs. 81301671; 81371955).

\section{Availability of data and materials}

Data sharing not applicable to this article as no datasets were generated or analyzed during the current study.

\section{Authors' contributions}

Dr. JW analyzed and interpreted the patient data regarding the double approach dealing with the proximal fibular osteosarcoma and was a major contributor in writing the manuscript. Dr. CZ performed the data collective work. Dr. JW and Dr. H-bH made the plan preoperatively and performed the operation together. Dr. H-bH was in charge of the study design. All authors read and approved the final manuscript.

\section{Ethics approval and consent to participate}

Clinical information of this study were obtained by chart reviews and with the approval of the Committee on Clinical Investigation of Xiangya Hospital, Central South University.

\section{Consent for publication}

The informed consents were signed by all patients permitting to use their medical information. If needed, please contact the author for these consents.

\section{Competing interests}

The authors declare that they have no competing interests.

\section{Publisher's Note}

Springer Nature remains neutral with regard to jurisdictional claims in published maps and institutional affiliations.
Received: 17 August 2017 Accepted: 9 March 2018

Published online: 27 March 2018

\section{References}

1. Malawer MM, Sugarbarker PH. Musculoskeletal cancer surgery:treatment of sarcomas and allied diseases. Springer publishers, 2001.

2. Kramers-de Quervain IA, Läuffer JM, Käch K, Trentz O, Stüssi E. Functional donor-site morbidity during level and uphill gait after a gastrocnemius muscle-flap procedure. J Bone Joint Surg Am. 2001;83-A(2):239-46.

3. Yeap JS, Birch $R$, Singh D. Long-term results of tibialis posterior tendon transfer for drop-foot. Int Orthop. 2001:25(2):114-8.

4. Enneking WF, Spanier SS, Goodman MA. A system for the surgical staging of musculoskeletal sarcoma. Clin Orthop Relat Res. 1980;(153):106-20.

5. Enneking WF, Dunham W, Gebhardt MC, Malawar MM, Pritchard DJ. A system for the functional evaluation of reconstructive procedures after surgical treatment of tumors of the musculoskeletal system. Clin Orthop Relat Res. 1993;286:241-6.

6. Erler K, Demiralp B, Ozdemir MT, Basbozkurt M. Treatment of proximal fibular tumors with en bloc resection. Knee. 2004;11:489-96.

7. Li X, Moretti VM, Ashana AO, Lackman RD. Impact of close surgical margin on local recurrence and survival in osteosarcoma. Int Orthop. 2012 Jan;36(1):131-7

8. Xu M, Xu S, Yu X. Marginal resection for osteosarcoma with effective neoadjuvant chemotherapy: long-term outcomes. World J Surg Oncol. 2014;12:341

9. Kanazawa Y, Tsuchiya H, Nonomura A, Takazawa K, Yamamoto N, Tomita K. Intentional marginal excision of osteosarcoma of the proximal fibula to preserve limb function. J Orthop Sci. 2003;8:757-61.

10. Reddy Kl, Wafa H, Gaston CL, Grimer RJ, Abudu AT, Jeys LM, Carter SR, Tillman RM. Does amputation offer any survival benefit over limb salvage in osteosarcoma patients with poor chemonecrosis and close margins? Bone joint J. 2015;97-B(1):115-20.

11. Ozkan T, Tuncer S, Ozturk K, Aydin A, Ozkan S. Tibialis posterior tendon transfer for persistent drop foot after peroneal nerve repair. J Reconstr Microsurg. 2009:25(3):157-64

12. Bickels J, Kollender Y, Pritsch T, Meller I, Malawer MM. Knee stability after resection of the proximal fibula. Clin Orthop Relat Res. 2007:454:198-201.

13. Takeda A, Tsuchiya H, Mori Y, Tanaka S, Kikuchi S, Tomita K. Anatomical aspects of biopsy of the proximal fibula. Int Orthop. 2001:24:335-7.

14. Einoder PA, Choong PF. Tumors of the head of the fibula: good function after resection without ligament reconstruction in 6 patients. Acta Orthop Scand. 2002:73:663-6.

15. Abdel MP, Papagelopoulos PJ, Morrey ME, Wenger DE, Rose PS, Sim FH. Surgical management of 121 benign proximal fibula tumors. Clin Orthop Relat Res. 2010;468:3056-62.

16. Abdel MP, Papagelopoulos PJ, Morrey ME, et al. Malignant proximal fibular tumors: surgical management of 112 cases. J Bone Joint Surg Am. 2012 94(22):e165.

17. Shapeero LG, De Visschere PJ, Verstraete KL, Poffyn B, Forsyth R, Sys G, Uyttendaele D. Post-treatment complications of soft tissue tumours. Eur J Radiol. 2009;69(2):209-21.
Submit your next manuscript to BioMed Central and we will help you at every step:

- We accept pre-submission inquiries

- Our selector tool helps you to find the most relevant journal

- We provide round the clock customer support

- Convenient online submission

- Thorough peer review

- Inclusion in PubMed and all major indexing services

- Maximum visibility for your research

Submit your manuscript at www.biomedcentral.com/submit
Biomed Central 